\title{
Atividade de óleos e extratos vegetais sobre germinação carpogênica e crescimento micelial de Sclerotinia sclerotiorum
}

\author{
Activity of plant extracts on the carpogenic \\ germination and mycelial growth of Sclerotinia sclerotiorum
}

\author{
Cláudia de Souza Zanella1*, Walber Luiz Gavassoni ${ }^{1}$, \\ Lilian Maria Arruda Bacchi ${ }^{1}$, Anelise Samara Nazari Formagio ${ }^{1}$
}

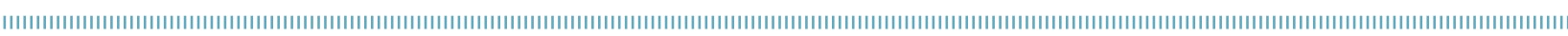

\begin{abstract}
RESUMO: A germinação carpogênica e o crescimento micelial de Sclerotinia sclerotiorum foram avaliados sob extratos metanólicos de Annona cacans, A. coriacea, A. crassiflora, A. dioica, A. sylvatica, Geophila repens, Guettarda viburnoides, Palicourea crocea, Schinus terebinthifolius e Trichilia silvatica, e sob as fraçôes hexânica, hidrometanólica, clorofórmica e acetato de etila de $A$. cacans e óleo essencial de $S$. terebinthifolius. A concentraçáo utilizada foi de 1.000 ppm para os extratos e de 100 ppm para as fraçóes. Os extratos vegetais e as fraçôes foram incorporados em meio ágar-água, que foi vertido em caixas gerbox com 20 escleródios. O crescimento micelial foi avaliado em óleo essencial de S. terebinthifolius, nas concentrações de 0, 100 e 1.000 ppm, incorporado ao meio BDA (Batata-Dextrose-Ágar). A germinaçáo carpogênica apresentou-se menor sob os extratos de $G$. repens, $P$. crocea e $S$. terebinthifolius e sob as fraçóes acetato de etila e clorofórmica de $A$. cacans. O número de apotécios formados por gerbox foi menor com o extrato de $A$. cacans. $\mathrm{O}$ crescimento micelial apresentou $10 \%$ de inibição na maior concentração do óleo essencial de S. terebinthifolius.
\end{abstract}

PALAVRAS-CHAVE: escleródio; apotécio; mofo branco.

\begin{abstract}
The effect of methanolic extracts of Annona cacans, A. coriacea, A. crassiflora, A. dioica, A. sylvatica, Geophila repens, Guettarda viburnoides, Palicourea crocea, Schinus terebinthifolius $e$ Trichilia silvatica, and $A$. cacans hexane, ethyl etila, aqueous and chloroform fractions and the essential oil of $S$. terebinthifolius on mycelial growth and carpogenic germination of Sclerotinia sclerotiorum was evaluated. The concentrations are 1,000 ppm for the extracts and $100 \mathrm{ppm}$ for the fractions. To evaluate the germination, carpogenic, extracts and fractions were incorporated in agar-water that was poured into gerboxes where 20 sclerotia were distributed. To evaluate the mycelial growth, essential oil of $S$. terebinthifolius in concentrations of 0,100 and 1,000 ppm was incorporated into the PDA and then poured into Petri dishes, to where pathogen mycelial discs were transferred. Extracts of $G$. repens, P. crocea and S. terebinthifolius and fractions ethyl acetate and chloroform of Annona cacans reduced the carpogenic germination of sclerotia of $S$. sclerotiorum and the extract of $A$. cacans reduced the number of apothecia formed. Mycelial growth showed $10 \%$ inhibition at the highest concentration of essential oil of $S$. terebinthifolius.
\end{abstract}

KEYWORDS: sclerotia; apothecium; white mold. 


\section{INTRODUÇÃO}

O fungo Sclerotinia sclerotiorum (Lib.) de Bary, agente causal da doença conhecida como mofo branco ou podridáo de esclerotínia, pode infectar mais de 400 espécies de plantas entre monocotiledôneas e dicotiledôneas (Bolland; Hall, 1994). Este fungo está distribuído em todas as regióes produtoras, sejam elas temperadas, subtropicais ou tropicais, e pode atacar culturas como batata, ervilha, feijão, girassol e soja.

A procura por vegetais e seus produtos livres de agrotóxicos é crescente, estimulando a busca por novas medidas de proteção das plantas contra as doenças. Dentro deste contexto, a atividade de compostos secundários presentes em extratos ou óleos essenciais de plantas medicinais pode se constituir em mais uma forma de controle alternativo de doenças em plantas (STANGARLin et al., 1999).

As plantas têm a capacidade de produzir metabólitos secundários, como fenóis, ácidos fenólicos, quinonas, flavonas, flavonoides, taninos, cumarinas, terpenoides e alcaloides. Em muitos casos, essas substâncias atuam como defesa da planta contra micro-organismos, insetos e herbívoros. Cientistas de diversos campos têm investigado as atividades antimicrobianas das plantas demonstrando a ação inibitória a vários grupos de micro-organismos devido à produçáo de fitoquímicos (CAWAN, 1999).

Extratos ou óleos essenciais de diversas espécies foram avaliados e tiveram seu efeito comprovado no controle de fungos fitopatogênicos, como é o caso do gengibre (Rodrigues et al., 2007), arruda, carqueja e manjericão (Stangarlin et al., 1999), Annona cacans e A. crassiflora (Lima et al., 2007), Annona sp. (Silva et al., 2008) e Schinus terebinthifolius (Lima et al., 2010), evidenciando o potencial do uso de extratos e óleos vegetais como alternativa aos fungicidas químicos.

SiLva et al. (2008), ao testarem os extratos de folhas e do cerne e córtex da raiz e do caule da "fruta-do-conde" (Annonaceae), verificaram que o extrato hexânico do cerne do caule da planta foi ativo contra o crescimento micelial de S. sclerotiorum. Os autores sugerem que o princípio ativo contra o patógeno deve estar presente em maior concentraçấo no cerne do caule do que nas demais partes da planta. Rodrigues et al. (2007) verificaram que o extrato aquoso de gengibre inibiu o crescimento micelial de $S$. sclerotiorum em $92,5 \%$, e em quase $30 \%$ a produção de escleródios na concentração de $25 \%$.

Diante do exposto, o objetivo deste trabalho foi avaliar a germinação carpogênica de escleródios de S. sclerotiorum sob diferentes extratos e óleos de espécies vegetais, assim como avaliar o crescimento micelial do patógeno sob diferentes concentraçōes do óleo essencial de S. terebinthifolius.

\section{MATERIAL E MÉTODOS}

Foram realizados dois experimentos, sendo o primeiro com cinco ensaios, para avaliar a germinação carpogênica, e o segundo com um ensaio para avaliar o crescimento micelial de S. sclerotiorum. Os experimentos foram conduzidos no Laboratório de Microbiologia Agrícola e Fitopatologia da Faculdade de Ciências Agrárias da Universidade Federal da Grande Dourados (UFGD), no período de maio de 2010 a janeiro de 2012.

\section{Obtenção, multiplicação e manutenção do inóculo}

Os isolados de S. sclerotiorum foram obtidos em área naturalmente infestada pelo patógeno no município de Chapadáo do Sul (MS). Os escleródios foram produzidos a partir da repicagem do micélio do fungo para erlenmeyers contendo discos de cenoura previamente autoclavados. Os frascos foram incubados a $25^{\circ} \mathrm{C}$, em escuro pleno, por 30 dias. Após esse período, os escleródios formados foram retirados dos frascos, lavados em água corrente e armazenados a $5^{\circ} \mathrm{C}$ até a sua utilização nos experimentos.

\section{Delineamento experimental e análise de dados}

Os dados expressos em porcentagem foram transformados em arco seno da $\sqrt{ }(\mathrm{x}+1) / 100$, e os demais dados, em $\sqrt{x}_{\mathrm{x}+1}$. Foi realizada a análise de variância com o auxílio do programa SISVAR (Ferreira, 2011), e as médias foram comparadas pelo teste de Tukey a 5\% de probabilidade. Os dados de germinaçáo carpogênica foram submetidos à análise de regressão entre o tempo de incubação (dias), como fator independente, e a germinação carpogênica (\%) como variável dependente para os extratos testados.

\section{Espécies vegetais}

Folhas das espécies vegetais Annona cacans, Annona crassiflora, Annona coriacea, Annona sylvatica e Trichilia silvatica foram coletadas próximo à cidade de Dourados (MS). As espécies Geophila repens, Palicourea crocea e Guettarda viburnoides foram coletadas no Parque Ivinhema, no município de Ivinhema (MS). Frutos, folhas e caules de Schinus terebinthifolius foram coletados no Horto de Plantas Medicinais da UFGD, no município de Dourados (MS). As espécies foram identificadas pela professora Dr. Zefa Valdevina Pereira, e as exsicatas sob registro A. cacans (DDMS 3818), A. coriacea (DDMS 186), A. crassiflora (DDMS 4599), A. dioica (DDMS 4598), A. sylvatica (DDMS 4600), G. repens (DDMS 4467), G. viburnoides (DDMS 3520), P. crocea (DDMS 4448), S. terebinthifolius 
(DDMS 4602) e T. silvatica (DDMS 4662) encontram-se depositadas no Herbário da Faculdade de Ciências Biológicas e Ambientais (FCBA/UFGD).

\section{Preparação, fracionamento e extração do óleo essencial das espécies vegetais}

O material vegetal (folhas) das espécies foi desidratado em estufa de ar circulante à temperatura de $55^{\circ} \mathrm{C}$ e triturado em moinho de facas. O extrato metanólico foi obtido por maceraçáo exaustiva com metanol. Os extratos foram submetidos ao particionamento líquido-líquido, com hexano, clorofórmico e acetato de etila, que, com posterior evaporaçáo dos solventes em rota evaporador, resultaram nas fraçóes hexânica, clorofórmica, acetato de etila e hidrometanólica. Para obtenção do óleo essencial, frutos de $S$. terebinthifolius foram submetidos à hidrodestilação em aparelho Clevenger por quatro horas (Gottlieb; Magalhães, 1960) O óleo essencial obtido foi lavado com hexano e seco com sulfato de sódio anidro.

\section{Germinação carpogênica sob diferentes extratos vegetais}

Para a avaliação da germinação carpogênica foram realizados cinco ensaios, em delineamento inteiramente casualizado, com 10 repetiçóes e o número de tratamentos variando para cada ensaio, conforme descrito na Tabela 1 .

Os extratos e partiçôes foram dissolvidos em tubos de ensaio contendo água esterilizada e autoclavada, na proporção de $0,5 \mathrm{~g}$ de extrato e $9,5 \mathrm{~mL}$ de água. Após agitação dos tubos em agitador Vortex para a dissoluçáo dos extratos, a soluçáo foi vertida em $490 \mathrm{~mL}$ do meio ágar-água e transferida para caixas tipo gerbox $(11,5 \times 11,5 \times 3,5 \mathrm{~cm})$. Vinte escleródios foram, entâo, distribuídos sobre o meio, após sua solidificação, e os gerbox foram incubados a $18^{\circ} \mathrm{C}$ com fotoperíodo de $12 \mathrm{~h}$ luz / $12 \mathrm{~h}$ escuro. A concentração final dos extratos e do óleo foi de $1.000 \mathrm{ppm}$, e das fraçôes, de $100 \mathrm{ppm}$.

As avaliaçôes iniciaram-se a partir da verificação da emissáo de estipes. Foi enumerado o número total de escleródios com emissáo de estipes e de apotécios, assim como o número total de estipes e de apotécios por unidade experimental. Com base no número de escleródios com apotécios, calculou-se a porcentagem de germinação carpogênica. Foi considerada germinação carpogênica a formação de apotécios pelo escleródio.

\section{Crescimento micelial sob diferentes extratos vegetais}

Para a avaliaçáo do crescimento micelial foi realizado um ensaio, em delineamento inteiramente casualizado, com 10 repetiçóes. Os tratamentos constaram das concentraçóes de 0 , 100 e 1.000 ppm de óleo essencial de S.terenbinthifolius, e o fungicida procimidone $(150 \mathrm{~g} / 100 \mathrm{~L})$.
Tabela 1. Ensaios realizados da germinação carpogênica de S. sclerotiorum sob extratos metanólicos (1.000 ppm) e frações obtidas a partir da partição dos extratos vegetais (100 ppm).

\begin{tabular}{|c|c|}
\hline Ensaio & Tratamentos \\
\hline \multirow{6}{*}{1} & Annona cacans \\
\hline & Annona coriacea \\
\hline & Annona sylvatica \\
\hline & Annona crassiflora \\
\hline & Annona dioica \\
\hline & Testemunha (somente ágar/água) \\
\hline \multirow{8}{*}{2} & Annona cacans \\
\hline & Annona cacans - fração hexânica \\
\hline & Annona cacans - fração clorofórmica \\
\hline & Annona cacans - fração acetato de etila \\
\hline & Annona cacans - fração hidrometanólica \\
\hline & Schinus terebinthifolius \\
\hline & Fungicida (i.a. Procimidone na dose de $150 \mathrm{~g} / 100 \mathrm{~L}$ ) \\
\hline & Testemunha (somente ágar/água) \\
\hline \multirow{5}{*}{3} & Trichilia silvatica \\
\hline & Geophila repens \\
\hline & Palicourea crocea \\
\hline & Guettarda viburnoides \\
\hline & Testemunha (somente ágar/água) \\
\hline \multirow{5}{*}{4} & Palicourea crocea \\
\hline & Geophila repens \\
\hline & Guettarda viburnoides \\
\hline & Testemunha (somente ágar/água) \\
\hline & 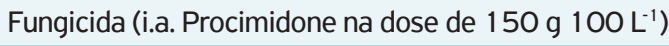 \\
\hline \multirow{4}{*}{5} & Schinus terebinthifolius (caule) \\
\hline & Schinus terebinthifolius (folha) \\
\hline & Schinus terebinthifolius (óleo essencial) \\
\hline & 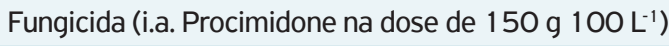 \\
\hline
\end{tabular}

O óleo essencial de S. terebinthifolius e o fungicida Procimidone foram homogeneizados no meio Batata-Dextrose-Ágar (BDA) e vertidos em placas de Petri. Após a solidificação do meio, discos miceliais do patógeno com $0,3 \mathrm{~cm}$ de diâmetro, provenientes de cultura pura em meio $\mathrm{BDA}$, foram transferidos para o centro das placas. As placas foram incubadas a temperatura de $25^{\circ} \mathrm{C}$ e fotoperíodo de $12 \mathrm{~h}$ luz / $12 \mathrm{~h}$ escuro. As avaliaçôes, realizadas diariamente, iniciaram-se 24 horas após a incubação e foram encerradas 96 horas depois, mensurando-se o diâmetro das colônias em dois eixos ortogonais, com o auxílio de uma régua milimetrada. A inibiçáo do crescimento do patógeno (\%) foi obtida comparando-se o diâmetro médio, em cm, entre as colônias sob tratamentos e a testemunha, após quatro dias de incubação, por meio da fórmula: PIC $=[$ (diâmetro da testemunha-diâmetro do tratamento) / diâmetro da testemunha] x 100 . 


\section{RESULTADOS E DISCUSSÃO}

\section{Germinação carpogênica sob diferentes extratos vegetais}

Observaram-se que alguns dos extratos metanólicos avaliados afetaram a germinação carpogênica de $S$. sclerotiorum. No primeiro ensaio (Fig. 1), utilizando os extratos metanólicos de A. cacans, A. coriacea, A. crassiflora, A. sylvatica e A. dioica, apenas na avaliação realizada 43 dias após incubação (DAI) observou-se diferença na germinação carpogênica entre os tratamentos (Tabela 2), na qual a testemunha apresentou menor porcentagem de germinação carpogênica em relação à $A$. cacans, $A$. coriacea e $A$. dioica, 72,75 e $71 \%$, respectivamente. Entretanto, nas avaliaçôes posteriores, a germinação carpogênica da testemunha aumentou (Fig. 1), igualando-se aos demais tratamentos. $\mathrm{O}$ extrato de $A$. cacans, aos 50 DAI, inibiu a emissão do número de apotécios em relação à testemunha e aos extratos de $A$. dioica e $A$. coriacea (Tabela 2).

Embora não tenham apresentado efeito sobre a germinação carpogênica de $S$. sclerotiorum, extratos hexânicos de A. coriacea e $A$. crassiflora apresentaram inibição da germinação de uredósporos de Phakopsora pachyrhizi na ordem de 93,9 e 96,25\%, respectivamente (Lima et al., 2007). O fungo Alternaria solani teve seu crescimento micelial inibido em 26 e 17,5\%, quando exposto aos extratos hexânicos de A. crassiflora e $A$. coriacea, respectivamente (MARQues et al., 2007). Entretanto, extratos etanólicos de $A$. crassiflora não apresentaram efeito no crescimento micelial de Fusarium solani, mesmo na maior concentração (RÊGo et al., 2011).

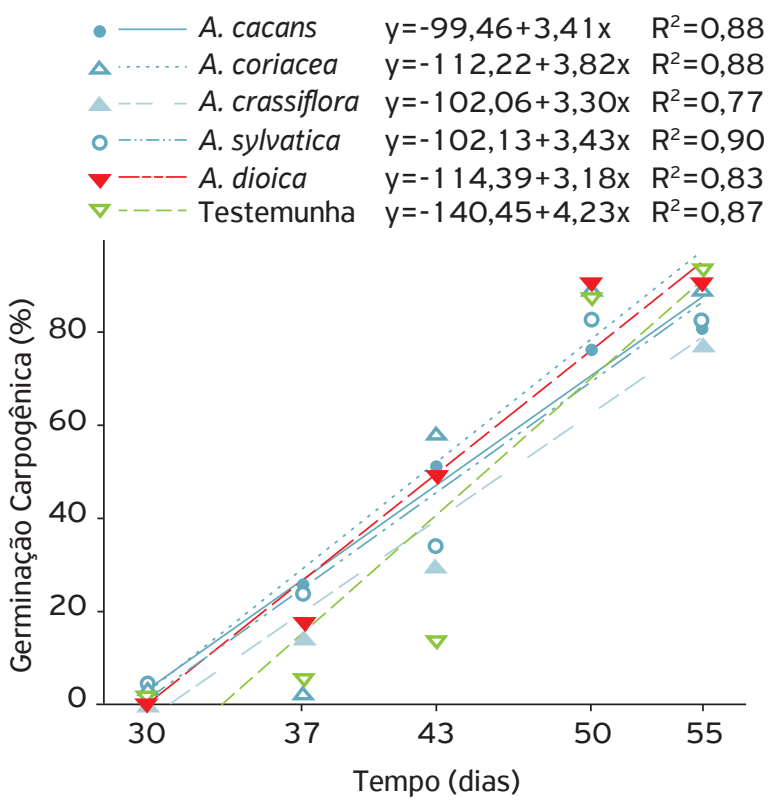

Figura 1. Germinação carpogênica (\%) de S. sclerotiorum sob extratos metanólicos (1.000 ppm) de diferentes espécies de Annonaceae em função do tempo (dias) após a incubação.
Apesar da presença de polifenóis nos extratos metanólicos de $A$. coriacea, $A$. crassiflora e $A$. sylvatica (Formagio et al., 2010), estes não apresentaram nenhuma ação na germinação carpogênica de escleródios de S. sclerotiorum, sugerindo que os compostos presentes nestes extratos, na concentração utilizada, não afetam o patógeno em questão. São escassos os trabalhos avaliando a germinação carpogênica de S. sclerotiorum, mas, ao avaliarem o crescimento miceliogênico do patógeno em meio BDA, Silva et al. (2008) verificaram que apenas o extrato de cerne do caule de Annona sp. inibiu o crescimento micelial do patógeno, enquanto os extratos de folha e raiz náo apresentaram efeito sobre o fungo.

No segundo ensaio, a inibição da germinação carpogênica apresentou-se maior com o extrato metanólico de $S$. terebinthifolius e de $A$. cacans, e suas fraçóes acetato de etila e clorofórmica. $\mathrm{Na}$ avaliação realizada aos $78 \mathrm{DAI}$, a germinação carpogênica foi reduzida em 100, 94, 90 e 51\% sob os extratos de fração acetato de etila de $A$. cacans, fraçáo clorofórmica de $A$. cacans, extratos de $S$. terebinthifolius e de A. cacans, respectivamente (Tabela 3 ).

O terceiro ensaio foi realizado com os extratos metanólicos de $G$. repens, $P$. croceae, $G$. viburnoides, $T$. silvatica. Os dois primeiros extratos inibiram em $100 \%$ a germinação carpogênica dos escleródios em todas as épocas de avaliação, diferindo-se da testemunha. A germinação carpogênica sob os extratos de $G$. viburnoides e $T$. silvatica foi menor que na testemunha somente na primeira avaliação, sendo que, nas demais avaliaçóes, não houve diferença entre esses tratamentos e a testemunha (Tabela 4).

No quarto ensaio, foram utilizados os extratos de P. crocea, G. repens, G. viburnoides, além do fungicida procimidone, sendo que o resultado do segundo ensaio se repetiu, com $G$. repens e $P$. crocea inibindo a germinaçáo carpogênica em relação ao extrato de $G$. viburnoides e à testemunha (Tabela 5).

Tabela 2. Germinação carpogênica e número de apotécios formados por unidade experimental de escleródios de S. sclerotiorum sob extratos metanólicos (1.000 ppm) de diferentes espécies de Annonaceae aos 43 e aos 50 dias de incubação, respectivamente.

\begin{tabular}{|c|c|c|c|c|}
\hline Tratamento & \multicolumn{2}{|c|}{ GC (\%) aos 43 DAI } & \multicolumn{2}{|c|}{ NAF aos $50 \mathrm{DAl}$} \\
\hline A. cacans & 51,5 & a & 40,3 & $b$ \\
\hline A. sylvatica & 34,0 & $a b$ & 67,0 & $a b$ \\
\hline A. crassiflora & 29,5 & $a b$ & 53,7 & $a b$ \\
\hline A. dioica & 50,0 & a & 80,1 & $a$ \\
\hline A. coriacea & 58,5 & a & 79,6 & $a$ \\
\hline Testemunha & 14,5 & b & 79,9 & a \\
\hline CV (\%) & \multicolumn{2}{|c|}{46,9} & \multicolumn{2}{|c|}{22,6} \\
\hline
\end{tabular}

Médias seguidas pela mesma letra nas colunas não diferem entre si pelo teste de Tukey a 5\% de probabilidade.

GC: germinação carpogênica; DAl: dias de incubação; NAF: número de apotécios formados; CV: coeficiente de variação. 
Suffredini et al. (2006) consideraram o extrato da parte aérea de Palicourea guianensis uma fonte potencial de antibiótico a Staphyilococcus aureus e Enterococcus faecalis em razão da baixa concentração mínima inibitória a esses patógenos, demonstrando a atividade antimicrobiana do gênero. Entretanto, Jorge (2005) observou que o extrato bruto da planta $P$. crocea não foi ativo diante da $S$. aureus, Bacillus subtilis, Escherichia coli, Pseudomona aeruginosa e
Candida albicans, pois a concentração mínima inibitória do extrato bruto foi maior que $1.000 \mathrm{mg} / \mathrm{mL}$ para todos os micro-organismos.

Extratos de Trichilia elegans e T. clausenii não apresentaram efeito no crescimento micelial de Colletotrichum gloeosoporioides, sendo que este último estimulou o crescimento do patógeno (Sierra-HaYer et al., 2009), corroborando os resultados do presente estudo, em que o extrato

Tabela 3. Germinação carpogênica (\%) de S. sclerotiorum sob extratos metanólicos (1.000 ppm) de Anonna cacans, Schinus terebinthifolius, frações (100 ppm) hexânica, acetato de etila, hidrometanólica e clorofórmica de Anonna cacans e fungicida Procimidone ( $150 \mathrm{~g} / 100 \mathrm{~L})$ aos 36, 45, 53, 60, 70 e 78 dias após incubação.

\begin{tabular}{|c|c|c|c|c|c|c|c|c|c|c|c|c|}
\hline \multirow{3}{*}{$\begin{array}{l}\text { Tratamento } \\
\text { Annona cacans }\end{array}$} & \multicolumn{12}{|c|}{ Germinação Carpogênica (\%) } \\
\hline & \multicolumn{2}{|c|}{$36 \mathrm{DAl}$} & \multicolumn{2}{|c|}{$45 \mathrm{DAl}$} & \multicolumn{2}{|c|}{53 DAl } & \multicolumn{2}{|c|}{$60 \mathrm{DAl}$} & \multicolumn{2}{|c|}{$70 \mathrm{DAl}$} & \multicolumn{2}{|c|}{$78 \mathrm{DAl}$} \\
\hline & 0,0 & $b$ & 0,0 & $b$ & 1,0 & $b$ & 5,0 & bc & 6,5 & $b$ & 19,5 & c \\
\hline A. cacans - hexânica & 1,0 & $a b$ & 3,5 & $a b$ & 8,5 & $a b$ & 9,5 & $a b c$ & 20,0 & $b$ & 35,5 & $\mathrm{~b}$ \\
\hline A. cacans - clorofórmica & 0,0 & $\mathrm{~b}$ & 0,0 & $b$ & 0,0 & $\mathrm{~b}$ & 0,5 & c & 1,5 & c & 2,5 & $d$ \\
\hline A. cacans - acetato de etila & 0,0 & $\mathrm{~b}$ & 0,0 & $\mathrm{~b}$ & 0,0 & $b$ & 0,0 & c & 0,0 & c & 0,0 & $d$ \\
\hline A. cacans - hidrometanólica & 10,0 & $a$ & 18,0 & $a$ & 32,5 & $a$ & 34,0 & a & 64,0 & $a$ & 83,5 & $a$ \\
\hline S. terebinthifolius & 0,0 & $b$ & 0,0 & $b$ & 0,0 & $b$ & 0,0 & c & 0,0 & c & 4,0 & $\mathrm{~cd}$ \\
\hline Procimidone & 0,0 & $b$ & 0,5 & $b$ & 1,5 & $b$ & 1,5 & bc & 2,0 & c & 2,5 & $\mathrm{~d}$ \\
\hline Testemunha & 1,0 & $a b$ & 5,0 & $a b$ & 9,5 & $a b$ & 14,5 & $a b$ & 30,0 & $b$ & 44,0 & $b$ \\
\hline CV (\%) & \multicolumn{2}{|c|}{44,1} & \multicolumn{2}{|c|}{93,0} & \multicolumn{2}{|c|}{79,6} & \multicolumn{2}{|c|}{70,1} & \multicolumn{2}{|c|}{40,5} & \multicolumn{2}{|c|}{38,7} \\
\hline
\end{tabular}

Médias seguidas pela mesma letra nas colunas não diferem entre si pelo teste de Tukey a $5 \%$ de probabilidade. DAl: dias após incubação; CV: coeficiente de variação.

Tabela 4. Germinação carpogênica (\%) de S. sclerotiorum sob extratos metanólicos (1.000 ppm) de Geophila repens, Guettarda viburnoides, Palicourea crocea e Trichilia silvatica, aos 28, 35, 43 e 50 dias após incubação.

\begin{tabular}{|c|c|c|c|c|c|c|c|c|}
\hline \multirow{3}{*}{$\begin{array}{l}\text { Tratamento } \\
\text { Testemunha }\end{array}$} & \multicolumn{8}{|c|}{ Germinação Carpogênica (\%) } \\
\hline & \multicolumn{2}{|c|}{$28 \mathrm{DAl}$} & \multicolumn{2}{|c|}{35 DAl } & \multicolumn{2}{|c|}{43 DAl } & \multicolumn{2}{|c|}{$50 \mathrm{DAl}$} \\
\hline & 1,4 & $\mathrm{a}$ & 22,3 & a & 23,2 & $\mathrm{a}$ & 24,5 & a \\
\hline Guettarda viburnoides & 0,0 & $b$ & 14,4 & $a$ & 14,4 & $a$ & 12,0 & $a b$ \\
\hline Trichilia silvatica & 0,0 & $b$ & 11,0 & $a b$ & 11,5 & $a b$ & 13,5 & a \\
\hline Palicourea crocea & 0,0 & $b$ & 0,0 & $b$ & 0,0 & $b$ & 0,0 & $b$ \\
\hline Geophila repens & 0,0 & $b$ & 0,0 & $b$ & 0,0 & $b$ & 0,0 & $b$ \\
\hline CV (\%) & \multicolumn{2}{|c|}{28,8} & \multicolumn{2}{|c|}{65.2} & \multicolumn{2}{|c|}{65,0} & \multicolumn{2}{|c|}{61,6} \\
\hline
\end{tabular}

Médias seguidas pela mesma letra nas colunas não diferem entre si pelo teste de Tukey a $5 \%$ de probabilidade.

DAl: dias após incubação; CV: coeficiente de variação.

Tabela 5. Germinação carpogênica (\%) de S. sclerotiorum sob extratos metanólicos (1.000 ppm) de Geophila repens, Guettarda viburnoides, Palicourea crocea e fungicida procimidone $(150 \mathrm{~g} / 100 \mathrm{~L})$ aos 30, 38, 45 e 52 dias após incubação.

\begin{tabular}{|c|c|c|c|c|c|c|c|c|}
\hline \multirow{3}{*}{$\begin{array}{l}\text { Tratamento } \\
\text { Guettarda viburnoides }\end{array}$} & \multicolumn{8}{|c|}{ Germinação Carpogênica (\%) } \\
\hline & \multicolumn{2}{|c|}{$30 \mathrm{DAl}$} & \multicolumn{2}{|c|}{$38 \mathrm{DAl}$} & \multicolumn{2}{|c|}{$45 \mathrm{DAl}$} & \multicolumn{2}{|c|}{$52 \mathrm{DAl}$} \\
\hline & 8,5 & a & 21,5 & a & 29,0 & a & 30,5 & a \\
\hline Palicourea crocea & 0,5 & $b$ & 2,5 & $b$ & 2,5 & c & 3,5 & $\mathrm{C}$ \\
\hline Geophila repens & 0,5 & $b$ & 4,5 & $b$ & 8,5 & $b$ & 12,0 & $\mathrm{~b}$ \\
\hline Procimidone & 0,0 & $b$ & 0,5 & $c$ & 5,5 & $b c$ & 11,0 & $\mathrm{~b}$ \\
\hline Testemunha & 1,5 & $a b$ & 9,5 & $a b$ & 20,0 & $a b$ & 25,5 & a \\
\hline CV (\%) & \multicolumn{2}{|c|}{62,8} & \multicolumn{2}{|c|}{52,4} & \multicolumn{2}{|c|}{40,8} & \multicolumn{2}{|c|}{32,1} \\
\hline
\end{tabular}

Médias seguidas pela mesma letra nas colunas não diferem entre si pelo teste de Tukey a $5 \%$ de probabilidade.

DAl: dias após incubação; CV: coeficiente de variação. 
de Trichilia sp. não diferiu da testemunha nos dois ensaios em que foi testado.

O extrato de Guettada speciosa possui alcaloides, flavonoides, triterpenoides, carboidratos, taninos e fenóis que se mostraram efetivos na inibição de Aspergillus niger e Candida albicans (Thamizhvanah et al., 2010). Entretanto, para a germinaçáo carpogênica do patógeno estudado no presente trabalho, esses compostos náo apresentaram atividade inibitória.

No quinto ensaio foram utilizados óleo essencial e extratos de caule e folha de $S$. terebinthifolius. O óleo essencial teve comportamento semelhante ao fungicida na primeira avaliação, realizada aos 32 dias após a incubação (Tabela 6).

Para infectar o hospedeiro, o fungo $S$. sclerotiorum necessita de uma fonte exógena de energia (Abawi; Grogan, 1979), que em muitas culturas são as flores (STEADMAN, 1983), por isso, a época do florescimento é crucial para o estabelecimento da doença. Ao estudarem a podridão de esclerotínia em plantas de colza, Young; Werner (2012) verificaram que as pétalas das flores são a principal rota de infecçấo do patógeno. Desta forma, considerando que a janela de infecção pelo patógeno ocorre no florescimento, mesmo os extratos que inibem apenas temporariamente a germinação carpogênica, ou seja, no período de florescimento da cultura, têm potencial para controle da doença, pois, quando ocorrer a liberação de esporos pelo apotécio, o período de maior predisposição da cultura à infecção terá sido ultrapassado. Esse efeito foi observado neste trabalho, pois na primeira avaliação a germinação carpogênica sob o óleo de S. terebinthifolius foi baixa, semelhantemente à germinação carpogênica sob o fungicida. Somente na segunda avaliação, realizada aos 40 dias, é que houve aumento de apotécios neste tratamento em relação ao fungicida (Tabela 6).

O efeito estimulante da germinação carpogênica sob alguns extratos pode ser positivo do ponto de vista do manejo do mofo branco, pois estimular a germinação de escleródios sob culturas não hospedeiras, na entressafra ou evitando-se a fase mais vulnerável da cultura à infecção pelo patógeno, pode diminuir a incidência da doença.

\section{Crescimento micelial sob diferentes extratos vegetais}

O crescimento micelial de S. sclerotiorum também foi avaliado nas concentraçôes de 0,100 e 1.000 ppm do óleo essencial de $S$. terebinthifolius. Nas avaliaçōes realizadas até 72 horas após a incubação, a maior concentração proporcionou inibição do crescimento da colônia. Entretanto, o fungo continuou a crescer, igualando-se à testemunha $(0 \mathrm{ppm})$ na última avaliação (Fig. 2). A inibição do crescimento micelial foi de $10 \%$ na maior concentração (Tabela 7).

Esses resultados estão de acordo com outros trabalhos, em que o patógeno $S$. sclerotiorum não foi afetado pela utilização de óleo ou extrato de Schinus. Pansera et al. (2011a)

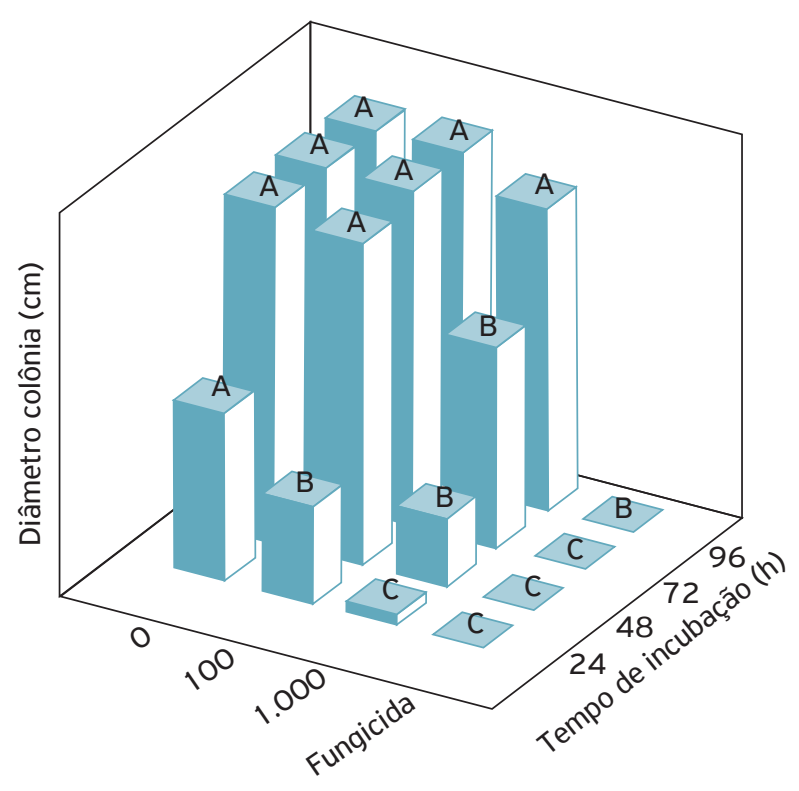

Figura 2. Diâmetro $(\mathrm{cm})$ da colônia de S. sclerotiorum em meio de cultura BDA, sob diferentes concentrações de óleo essencial de S. terebinthifolius e fungicida Procimidone (150 g/100 L), após 24, 48, 72 e 96 horas de incubação. Médias seguidas da mesma letra em cada tempo de avaliação, não diferem entre si pelo teste de Tukey a 5\% de probabilidade.

Tabela 6. Germinação carpogênica (\%) de S. sclerotiorum sob extratos metanólicos, óleo essencial (1.000 ppm) de Schinus terebinthifolius e fungicida procimidone $(150 \mathrm{~g} / 100 \mathrm{~L})$ aos 32, 40, 48 e 56 dias após incubação.

\begin{tabular}{|c|c|c|c|c|c|c|c|c|}
\hline \multirow{3}{*}{$\begin{array}{l}\text { Tratamento } \\
\text { Schinus terebinthifolius (caule) }\end{array}$} & \multicolumn{8}{|c|}{ Germinação Carpogênica (\%) } \\
\hline & \multicolumn{2}{|c|}{32 DAI } & \multicolumn{2}{|c|}{$40 \mathrm{DAI}$} & \multicolumn{2}{|c|}{48 DAI } & \multicolumn{2}{|c|}{56 DAI } \\
\hline & 27,5 & a & 83,0 & a & 91,3 & a & 92,5 & a \\
\hline Schinus terebinthifolius (óleo) & 7,5 & $b$ & 41,0 & a & 67,5 & a & 77,5 & a \\
\hline Schinus terebinthifolius (folha) & 18,8 & $a b$ & 43,0 & $a b$ & 52,5 & $a b$ & 56,3 & $a b$ \\
\hline Procimidone & 6,9 & $\mathrm{~b}$ & 16,0 & $\mathrm{~b}$ & 22,5 & $\mathrm{~b}$ & 24,5 & $\mathrm{~b}$ \\
\hline CV (\%) & \multicolumn{2}{|c|}{15,5} & \multicolumn{2}{|c|}{46,0} & \multicolumn{2}{|c|}{54,4} & \multicolumn{2}{|c|}{62,7} \\
\hline
\end{tabular}

Médias seguidas pela mesma letra nas colunas não diferem entre si pelo teste de Tukey a $5 \%$ de probabilidade. DAl: dias após incubação; CV: coeficiente de variação. 
Tabela 7. Inibição do crescimento micelial (\%) de S. sclerotiorum sob três concentrações de óleo essencial de S. terebinthifolius e fungicida Procimidone $(150 \mathrm{~g} / 100 \mathrm{~L})$, após 96 horas de incubação

\begin{tabular}{lcc} 
Tratamentos & \multicolumn{2}{c}{ Inibição (\%) } \\
\hline O ppm & 0,0 & c \\
\hline 100 ppm & 0,0 & c \\
\hline 1.000 ppm & 10,0 & b \\
\hline Procimidone & 100,0 & a \\
\hline CV (\%) & \multicolumn{3}{c}{32,1} \\
\hline
\end{tabular}

Médias seguidas pela mesma letra nas colunas não diferem entre si pelo teste de Tukey a $5 \%$ de probabilidade.

observaram que o óleo essencial de $S$. terebinthifolius não controlou o crescimento micelial de S. sclerotinia em nenhuma das concentraçóes testadas, e GARCia et al. (2012) verificaram que o extrato de $S$. molle inibiu somente $2,7 \%$ o crescimento micelial do fungo, náo diferindo da testemunha.

Entretanto, o crescimento micelial de Colletotrichum gloeosporioides foi inibido em média em 20\% nas concentraçôes de 3 e $4 \%$ do extrato de $S$. terebinthifolius quando comparado à testemunha, mostrando resultados efetivos na redução do desenvolvimento do patógeno (Lima et al., 2010). De acordo com Matos (1988), a mesma espécie botânica pode apresentar diferenças em sua composição química, em função de sua ocorrência em diferentes regióes. A análise cromatográfica do óleo essencial de S. terebinthifolius proveniente de frutos colhidos no horto de plantas medicinais da UFGD identificou predominância de monoterpenos em sua composiçáo, destacando-se como principal constituinte o $\beta$-pineno (Formagio et al., 2011), fitoconstituinte com ação inibitória em bactérias como Staphylococus aureus, S. epidermidis, Streptococcus pneumoniae e S. pyogenes (Leite et al., 2007). Portanto, sugerem-se que novos estudos sejam realizados utilizando outras concentraçóes do óleo proveniente de frutos para verificar seu efeito sobre o patógeno.

\section{CONCLUSÃO}

Os extratos de $A$. cacans, G. repens, P. crocea e as fraçóes clorofórmica e acetato de etila de $A$. cacans apresentaram atividade antifúngica na germinaçáo carpogênica de S. sclerotiorum.

O óleo essencial de S. terebinthifolius na concentração de $1.000 \mathrm{ppm}$ apresentou atividade antifúngica no crescimento micelial do patógeno.

\section{REFERÊNCIAS}

ABAWI, G.S.; GROGAN, R.G. Epidemiology of diseases caused by Sclerotinia species. Phytopathology, v.69, n.8, p.899-904, 1979.

BOLLAND, G.J.; HALL, R. Index of plant hosts of Sclerotinia sclerotiorum. Canadian Journal of Plant Pathology, v.16, n.2, p.93-108, 1994.

CAWAN, M.M. Plant products as antimicrobial agents. Clinical Microbiology Reviews, v.12, n.4, p.564-582, 1999.

FERREIRA, D.F. Sisvar: a computer statistical analysis system. Ciência e Agrotecnologia, v.35, n.6, p.1039-1042, 2011.

FORMAGIO, A.S.N.; IRIGUCHI, E.K.K.; ROVEDA, L.M.; VIEIRA, M.C.; CARDOSO, C.A.L.; ZARATE, N.A.H.; TABALDI, L.A.; KASSUYA, C.A.L. Chemical compositions and anti-inflammatory activity of the essential oil of Schinus terebinthifolius Raddi (Anacardiaceae) fruits. Latin American Journal of Pharmacy, v.30, n.8, p.1555-1559, 2011.

FORMAGIO, A.S.N.; MASETTO, T.E.; BALDIVIA, D.S.; VIEIRA, M.C.; ZARATE, N.A.H.; PEREIRA, Z.V. Potencial alelopático de espécies da família Annonaceae. Revista Brasileira de Biociências, v.8, n.4, p.349-354, 2010.
GARCIA, R.A.; JULIATTI, F.C.; BARBOSA, K.A.G.; CASSEMIRO, T.A. Atividade antifúngica de óleo e extratos vegetais sobre Sclerotinia sclerotiorum. Bioscience Journal, v.28, n. 1, p.48-57, 2012.

GOTTLIEB, O.R.; MAGALHÃES, M.T. Modified distillation trap. Chemist Analyst, v.49, n.4, p.114, 1960.

JORGE, T.C.M. Estudo químico e farmacológico de duas espécies da família rubiaceae: Cephalanthus glabratus e Palicourea crocea. 2005. 225f. Tese (Doutorado em Química) Universidade Estadual de Maringá, Maringá, 2005.

LEITE, A.M.; LIMA, E.O.; SOUZA, E.L.; DINIZ, M.F.F.M.; TRAJANO, V.N.; MEDEIROS, I.A. Inhibitory effect of $\beta$-pinene, $\alpha$-pinene and eugenol on the growth of potential infectious endocarditis causing Gram-positive bacteria. Revista Brasileira de Ciências Farmacêuticas, v.43, n. 1, p.121-126, 2007.

LIMA, N.B.; MARQUES, M.W.; CAIXETA, L.; NAUE, C.R. Avaliação do extrato de aroeira (Schinus terebinthifolius Raddi) sobre o crescimento de Colletotrichum gloeosporioides in vitro. In: JORNADA DE ENSINO, PESQUISA E EXTENSÃO, 10., 2010, Recife. Anais... Recife: UFRPE, 2010. 
LIMA, V.S.; MAGNANI ZAMBENEDETTI, E.B.; MARQUES, C.A.G. Avaliação in vitro do efeito de Annona crassiflora Mart e Annona coreacea Mart sobre a germinação de uredosporos do fungo Phakopsora pachyrhizi causador da ferrugem asiática na soja. In: CONGRESSO BRASILEIRO DE FITOPATOLOGIA, 40., 2007, Maringá. Fitopatologia Brasileira, v.32, 2007, p.S1 12.

MARQUES, C.A.G.; MAGNANI ZAMBENEDETTI, E.B.; LIMA, V.S.; ZAMBENEDETTI, G.B.; SOUPINSKI, J. Avaliação in vitro do extrato hexânico de Annona crassiflora Mart e Annona coreacea Mart sobre o fungo Alternaria solani (Ell. \& Martin) Jones \& Grout, causador da pinta-preta em tomateiro. In: CONGRESSO BRASILEIRO DE FITOPATOLOGIA, 40., 2007, Maringá. Fitopatologia Brasileira, v.32, 2007, p.S1 13.

MATOS, F.J.A. Introdução à Fitoquímica experimental. Fortaleza: EUFC, 1988. 128p.

PANSERA, M.R.; VICENÇO, C.B.; CONTE, R. I.; SARTORI, V.C.; RIBEIRO, R.T.S. Inibição do crescimento de Sclerotinia sclerotiorum (Lib.) de Bary com a utilização de óleos essenciais de Cinnamomum canphora Nees \& Eberm variedade linalolifera e Schinus terebinthifolius Raddi. In: Congresso Brasileiro de Fitopatologia, 44., 2011, Bento Gonçalves. Tropical Plant Pathology, v.36, 2011 , p.S588.

RÊGO, C.M.; SANTOS, F.S.; BOMFIM, B.S.A.; RODRIGUES, C.S.; COSTA, J.A.S.; MACHADO, L.L. Atividade antifúngica de extratos de Annona crassiflora (Mart.), Eugenia dysenterica (DC.) e Lafoensia pacari (St. Hil.) sobre Fusarium solani (Mart.) Sacc. In: CONGRESSO BRASILEIRO DE FITOPATOLOGIA, 44., 2011 , Bento Gonçalves. Tropical Plant Pathology, v.36, 201 1, p.S832.

RODRIGUES, E.; SCHWAN-ESTRADA, K.R.F.; FIORI-TUTIDA, A.C.G.; STANGARLIN, J.R.; CRUZ, M.E.S. Fungitoxicidade, atividade elicitora de fitoalexinas e proteção de alface em sistema de cultivo orgânico contra Sclerotinia sclerotiorum pelo extrato de gengibre. Summa Phytopathologica, v.33, n.2, p.124-128, 2007.
SIERRA-HAYER, J.F.; PASSADOR, M.M.; BALDIN, E.L.; BETELONI, F.G.; FURTADO, E.L. Efeito de extratos aquosos no crescimento micelial de Colletotrichum gloeosporioides isolado de seringueira. In: Congresso Brasileiro de Fitopatologia, 42., 2009, Rio de Janeiro. Tropical Plant Pathology, v.36, 2009, p.S728.

SILVA, L.J.; SILVA, M.S.; SILVA, L.N.; RABELLO, A.R.; ALVES, R.S.; ESPÍNDOLA, L.S.; PAULA, J.E.; VIEIRA, E.A.; LIMA, T.R.; ANJOS, J.R.N. Fungos fitopatogênicos de soja são sensíveis a extratos orgânicos de planta "fruta-do-conde", nativa do cerrado do gênero Annona sp. (Família Annonaceae). In: SIMPOSIO NACIONAL CERRADO, 9.; SIMPÓSIO INTERNACIONAL SAVANAS TROPICAIS, 2., 2008, Brasília. Anais... Planaltina: Embrapa Cerrados, 2008.

STANGARLIN, J.R.; SCHWAN-ESTRADA, K.R.F.; CRUZ, M.E.S.; NOZAKI, M.H. Plantas medicinais e controle alternativo de fitopatógenos. Biotecnologia Ciência \& Desenvolvimento, v.23, n. 11, p.16-21, 1999.

STEADMAN, J.R. White-mold - a serious yield-limited disease of bean. Plant Disease, v.67, n.4, p.346-350, 1983.

SUFFREDINI, I.B.; PACIENCIA, M.L.B.; VARELLA, A.D.; YOUNES, .N. Antibacterial activity of Brazilian amazon plant extracts. The Brazilian Journal of Infectious Diseases, v.10, n.6, p.400402, 2006.

THAMIZHVANAH, K.; KUMAR, P.; BACHALA, T.; MOHAN, D.M.; KRISHNAKISHORE, P.; KUMAR, K.P. Antibacterial and antifungal activities of various extracts of Guettarda speciosa L. International Journal of Phytopharmacology, v.1, n.1, p.2022, 2010.

YOUNG, C.S.; WERNER, C.P. Infection routes for Sclerotinia sclerotiorum in apetalous and fully petalled oilseed rape. Plant Pathology, v.61, n.4, p.730-738, 2012. 